\title{
Students' views on the need for hostile environment awareness training for South African emergency medical care students
}

\author{
C Vincent-Lambert, ${ }^{1}$ ND AET, NHD PSE, NHD FST, BTech EMC, MTech ED, PhD HPE; $\mathbf{R}$ Westwood, ${ }^{2}$ BHS EMC \\ ${ }^{1}$ Department of Emergency Medical Care, Faculty of Health Sciences, University of Johannesburg, Doornfontein Campus, South Africa \\ ${ }^{2}$ Department of Emergency Medical Care and Podiatry, Faculty of Health Sciences, University of Johannesburg, Doornfontein Campus, South Africa
}

Corresponding author: C Vincent-Lambert (clambert@uj.ac.za)

Background. South Africans experience high levels of contact crime, including assault, robbery and hijacking. Emergency medical services (EMS) are frequently called to the scene of such incidents. Their presence in these potentially hostile environments increases the risk of South African (SA) paramedics and paramedic students becoming victims of crime and violence. A 2015 study showed that $~ 66 \%$ of SA EMS staff reported being assaulted while on duty. During a 10-month period in 2016, Western Cape Province recorded $>40$ incidents of physical violence against their EMS personnel. Questions are being asked about how well prepared EMS staff are to operate in potentially hostile environments.

Objectives. To explore emergency medical care (EMC) students' experiences of violence and crime and their views on the need for hostile environment awareness training (HEAT) as part of their undergraduate degree programmes.

Methods. A self-designed, non-validated, cross-sectional online survey questionnaire was used to document the experiences, views and opinions of 113 undergraduate EMC students from 4 SA universities. The questionnaire consisted of 24 closed-ended questions with pre-set Likert scale options focusing on documenting participants' experiences, views and opinions regarding hostile environments and the need for HEAT.

Results. A high percentage of participants (92\%) indicated feeling unsafe while engaging in clinical learning shifts; $63 \%$ specified that they had personally witnessed violence against EMS crews, and $32 \%$ indicated that they had been assaulted while on duty. Unsurprisingly, $81 \%$ of the respondents felt that there is a need for inclusion of HEAT in the undergraduate curriculum.

Conclusions. Participation in clinical learning shifts in the current SA prehospital EMS environment increases the risk of exposure to potentially hostile environments. Consequently, students feel unsafe and support the inclusion of HEAT as part of their undergraduate degree programmes.

Afr J Health Professions Educ 2019;11(1):12-15. DOI:10.7196/AJHPE.2019.v11i1.1054

South Africans live in a society predisposed to high levels of contact and violent crime. Drivers of crime include poverty, unemployment and illegal immigration, and a Gini coefficient that is currently among the highest in the world. A Gini coefficient is a measure of inequality of income distribution or inequality of wealth distribution. These factors contribute to a situation where, on average, 51 people are murdered in South Africa (SA) every day. ${ }^{[1]}$ This is $\sim 5$ times the global average. Mortality due to interpersonal violence is $46 \%$, compared with a global average of $10 \%{ }^{[2]}$ Regrettably, the situation does not seem to be improving, with an increase in the incidence of assault with intent to cause grievous bodily harm, common assault, robbery with aggravating circumstances and car hijacking. ${ }^{[1]}$

Emergency medical services (EMS) personnel are commonly required to respond to incidents where they assist victims of crime and violence. In some instances, when ambulance crews arrive, the police are not yet on the scene and the situation remains volatile. Operating in such potentially hostile environments places paramedics and paramedic students at increased risk of becoming victims of crime and violence. This is by no means just an SA phenomenon. A recent Australian study found that $88 \%$ of their EMS personnel were exposed to violence while at work. Verbal abuse was the most prevalent (82\%), followed by intimidation (55\%), physical abuse (38\%), sexual harassment (17\%) and sexual abuse (4\%). ${ }^{[3,4]}$ A similar study on the prevalence of violence in the Swedish prehospital setting found that $66 \%$ of EMS personnel experienced threats and/or violence while at work. ${ }^{[5]}$ A study was also performed on the exposure of Iranian EMS staff to workplace violence, which found that $75 \%$ experienced at least one form of such violence. Verbal abuse was the most prevalent (71\%), followed by physical abuse (38\%). ${ }^{[6]}$

Holgate $^{[7]}$ reported that in SA, physical abuse is commonly encountered by EMS personnel as a result of their interactions with patients and bystanders. Holgate's study showed that of the EMS staff surveyed, $66 \%$ reported having experienced assault while on duty. ${ }^{[7]}$

Aside from interactions with patients and bystanders, another source of potential abuse is violent behaviour by criminals. It is thought that EMS personnel are seen as 'soft targets', as they are usually unarmed, travel into high-crime areas and often enter these areas after dark. Criminals target EMS staff to gain access to items such as valuable medical equipment, drugs, cell phones and electronic tablets. Unfortunately, there are no national statistics on the incidence of SA EMS personnel as victims of crime while on duty. Furthermore, there is no national system for EMS personnel to report crime, violence and abuse directed at them while on duty. This is concerning, given that during 10 months in 2016 Western Cape Province recorded $\geq 40$ incidents of physical violence against their EMS personnel. ${ }^{[8]}$

The abovementioned literature supports the view that, due to the nature of their duties, EMS personnel - locally and internationally - commonly encounter situations where the environment may be considered unsafe or hostile. It is evident that there is an increase in workplace violence 
experienced by SA EMS personnel. Crime, violence and unsafe working conditions are clearly undesirable. One of the negative consequences is the loss of skilled staff when qualified EMS personnel leave SA to practise abroad, where working and living conditions are believed to be safer. ${ }^{[9]}$

In response to the abovementioned concerns, certain law enforcement agencies and EMS providers offer hostile environment awareness training (HEAT) programmes for their staff. ${ }^{[10]}$ These HEAT programmes focus on developing one's ability to assess situations, recognise specific risk factors, and where possible avoid these risks. However, despite the existence of such programmes, the literature is limited regarding their real value and benefit in the higher education context.

Throughout their 4-year degree, emergency medical care (EMC) students are registered for clinical practice modules. These modules require students to work a predetermined number of prehospital shifts under the guidance of a clinical supervisor. The aim of these clinical shifts is to ensure that students gain exposure to the real-world EMC environment. During clinical learning shifts, students are designated to ambulances and response vehicles, attending to incidents that provide an opportunity to assess and treat patients in the real prehospital environment. ${ }^{[1]]}$ The exposure and experience obtained through clinical practice are important to provide students with the necessary clinical skills set to competently manage a broad spectrum of emergency situations and patients. ${ }^{[11]}$ Although anecdotal reports from EMC students include frequently experiencing and/or witnessing verbal and physical abuse against them and other EMS personnel during clinical learning shifts, we could not find literature quantifying or describing such experiences. With this in mind, we undertook this study, which aimed to formally explore and document experiences, views and opinions of SA EMC students regarding their exposure to hostile environments and the need for inclusion of HEAT as part of their undergraduate degree programmes.

\section{Methods}

This was a descriptive, quantitative, cross-sectional and exploratory study. ${ }^{[12]}$ A self-designed, non-validated, online survey questionnaire was used to document views and opinions of EMC students from 4 SA universities regarding their experiences of hostility during clinical learning and the need for HEAT. At the time of the study, there were 402 potential participants across 4 institutions who were invited to participate; we received 113 responses, giving a final response rate of $28 \%$. The questionnaire comprised closed questions in the form of statements to which the participants were required to indicate their level of agreement, using a Likert scale. The responses to each of the questions were tallied by using frequency data analysis. ${ }^{[13]}$ These data were captured on a Microsoft Excel (Microsoft, USA) spreadsheet and analysed using simple statistics, allowing the creation of tables that summarised responses. ${ }^{[13]}$

\section{Ethical approval}

Ethical approval for the study was given by the Faculty of Health Sciences Academic Ethics Committee, University of Johannesburg (ref. no. REC-0147-2017). In light of the research design, it was not necessary to identify individual students, patients, educators or supervising practitioners.

\section{Results \\ Demographics}

Of the 113 respondents who participated in the survey, $55.75 \%$ ( $n=63)$ were male and $44.25 \%(n=50)$ were female. The majority $(68.14 \% ; n=77)$ were white and 18 - 26 years of age. The spread of respondents by year of study was fairly even, with $21 \%$ in year 1,26\% in year 2, 33\% in year 3 and $20 \%$ in the final year of study.

\section{Experiences of violence against emergency medical services personnel}

Table 1 provides the participants' responses regarding their experiences of acts of violence towards them or other EMS personnel during clinical learning shifts. Table 2 summarises their views regarding personal safety and the perceived need for and value of HEAT.

\section{Discussion}

Our study aimed to provide insight into SA undergraduate EMC students with regard to hostile environments that they experienced during their prehospital clinical learning shifts and their perceived need for HEAT. The results are discussed under three main headings, i.e. demographics, experiences of violence and the need for HEAT.

\section{Demographics}

The black African population of SA is estimated to be $\sim 80.7 \%$ of the general population. Our sample was not demographically representative, as the majority (68.14\%) of our respondents were white, while only $31.86 \%$ were of other races. The reason remains unclear, as the invitation to participate was sent to all students from all races. Possible reasons for this finding might include the racial profile of EMC students from the 4 universities not reflecting that of the general population, and/or that all students did not share an equal interest in the study and/or all students did not have equal

Table 1. Responses regarding violence witnessed or experienced during clinical learning shifts

\begin{tabular}{lll}
\hline Statement & Yes, $\boldsymbol{n}(\%)$ & No, $\boldsymbol{n}(\%)$ \\
\hline There are times when I have felt unsafe while working during a prehospital shift & $104(92.04)$ & $9(7.96)$ \\
I have been verbally assaulted (e.g. sworn at, ridiculed, threatened) by a patient or bystander & $89(78.76)$ & $24(21.24)$ \\
I have been physically manhandled (e.g. pushed, pulled, assaulted) while working during a prehospital shift & $36(31.86)$ & $77(68.14)$ \\
I have been threatened by a patient or bystander & $67(59.29)$ & $46(40.71)$ \\
I have been threatened with a weapon (e.g. gun, knife, baton) while working during a prehospital shift & $26(23.01)$ & $87(76.99)$ \\
I have witnessed violence against EMS personnel while working during a prehospital shift & $71(62.83)$ & $42(37.17)$ \\
I have been on the scene where a firearm has been discharged (including SAPS) & $38(33.63)$ & $75(66.37)$ \\
I am aware of a fellow student who was involved in a vehicle hijacking or attempted vehicle hijacking & $85(75.22)$ & $28(24.78)$ \\
EMS = emergency medical services; SAPS = South African Police Service. & &
\end{tabular}


Table 2. Participants' views regarding personal safety and perceived need for and value of HEAT

\begin{tabular}{|c|c|c|c|c|c|}
\hline \multirow[b]{2}{*}{ Statements } & \multicolumn{5}{|c|}{ Responses, $n(\%)$} \\
\hline & Strongly agree & Agree & Neutral & Disagree & $\begin{array}{l}\text { Strongly } \\
\text { disagree }\end{array}$ \\
\hline $\begin{array}{l}\text { There are circumstances where I feel that I am at a higher risk of violence } \\
\text { compared with a 'normal student', i.e. a student in a mainstream academic } \\
\text { programme }\end{array}$ & $72(63.72)$ & $35(30.97)$ & $6(5.31)$ & 0 & 0 \\
\hline $\begin{array}{l}\text { I often consider myself to be at a higher risk of violence owing to the } \\
\text { irregular shift hours that I work }\end{array}$ & $44(38.94)$ & $52(46.02)$ & $12(10.62)$ & $3(2.65)$ & $2(1.77)$ \\
\hline $\begin{array}{l}\text { I often consider myself to be at a higher risk of vehicle hijacking owing to } \\
\text { the hours I work and distances I travel to work shift hours }\end{array}$ & $54(47.79)$ & $40(35.4)$ & $11(9.73)$ & $6(5.31)$ & $2(1.77)$ \\
\hline $\begin{array}{l}\text { I believe that adequate training and HEAT (as described in the information } \\
\text { letter) could mitigate risks, thereby creating a safer working environment }\end{array}$ & $53(46.9)$ & $46(40.71)$ & $9(7.96)$ & $3(2.65)$ & $2(1.77)$ \\
\hline $\begin{array}{l}\text { I would feel safer knowing that I had specific training on how to handle a } \\
\text { hostile environment, should it arise }\end{array}$ & $58(51.33)$ & $43(38.05)$ & $9(7.96)$ & $2(1.77)$ & $1(0.88)$ \\
\hline $\begin{array}{l}\text { I believe that violence against EMS personnel may be avoided if they have } \\
\text { adequate training, e.g. HEAT }\end{array}$ & $31(27.43)$ & $49(43.36)$ & $14(12.39)$ & $11(9.73)$ & $8(7.08)$ \\
\hline I feel that there is a need for the inclusion of HEAT in the EMC curriculum & $49(43.36)$ & $43(38.05)$ & 15 (13.27) & $4(3.54)$ & $2(1.77)$ \\
\hline
\end{tabular}

access to the internet to complete the online questionnaire. From a gender and age perspective, these distributions were more aligned with the norms expected for higher education in SA. The extent to which our results might have differed had our sample been different with regard to race, is currently unclear and is acknowledged as a potential limitation. Given SA's ethnic and cultural diversity, it would be valuable if future studies could explore whether or not perceptions and experiences of EMC students with regard to crime and hostile environments differ according to gender and race.

\section{Violence against emergency medical services personnel and students}

Exposure of paramedics to physical violence globally appears to vary considerably - from $2.9 \%$ to $79.5 \% \cdot{ }^{[3-6,9,14]}$ Our literature review found few published studies that specifically dealt with the incidence of violence against EMS students. Of our 113 respondents, 78.76\% reported being verbally abused (sworn at, ridiculed or threatened) either by a patient or bystander. This rate is more than three times higher than that cited in an Australian study, which found that $21.2 \%$ of their participants had been verbally assaulted during their clinical practice shifts. ${ }^{[4]}$

In the Australian study, with 133 respondents (paramedic students), only $1 \%$ had experienced assault during prehospital clinical practice shifts. This percentage is much lower than that in our study, where $32 \%$ of participants indicated that they had personal experience of assault. Assault in the context of our study included being pushed, shoved, hit or manhandled. Unsurprisingly, considering this, and as $83 \%$ had personally witnessed violence against EMS personnel, nearly all of our participants (92.04\%) indicated that they felt unsafe during their clinical practice prehospital shifts. ${ }^{[4]}$ A possible reason put forward in the Australian study for the low incidence of assault against their paramedic students was that their participants were not required to work at night, when it is thought that the majority of violence against EMS personnel takes place. In our study, $84.96 \%$ of participants considered themselves to be at higher risk of violence owing to the hours that they work. Most violent crimes in SA occur at night. ${ }^{[2]}$ Limiting SA paramedic students' exposure to night shifts might not be desirable, as these shifts are seen to be rich learning environments and many of the serious trauma cases linked to assault and motor vehicle collisions occur after dark. Furthermore, on qualifying, graduates are required to work at night, and limiting exposure to night shifts during their undergraduate training could leave students unprepared for the real working environment.

The undesirable consequences of working in hostile environments and the resultant concerns regarding physical security are numerous; school leavers consequently do not choose to study EMC, as it is seen as 'dangerous'. Crime affects all citizens of a country - not only members of EMS. Therefore, is it true that one's chances of being hijacked, assaulted or involved in a hostile environment are greater if ne is studying EMC? It would appear that both the literature and the results of this study lend support to this notion, with $94.69 \%$ of respondents indicating that they feel at higher risk of crime and violence compared with other students. Reasons might be linked to the areas where EMC students are sent to work and irregular shift hours.

Concerns regarding hijacking came across strongly, with $83.19 \%$ of participants indicating that they consider themselves to be at higher risk of vehicle hijacking, mainly due to the hours they work and distances they have to travel to shift work. Data from the SA Police Service (SAPS) indicate that from March 2015 to April 2016 there were 14602 reported cases of vehicle hijackings in SA. ${ }^{[1]}$ This roughly equates to 40 vehicles being hijacked daily. The majority of these hijackings take place at night, which is when the majority of violent crimes occur. ${ }^{[2]}$ Local data suggest that increased travel times, distances travelled and travelling at night, all of which are expected of SA EMC students, might increase the probability of being hijacked. Further studies are needed to empirically demonstrate if this is indeed the case and also to quantify the increased risk.

\section{Hostile environment awareness training}

There are specific HEAT programmes in many regions of the world for law enforcement, EMS and security and related personnel. ${ }^{[10]}$ These courses 
focus on developing one's ability to assess situations, recognise specific risk factors, and where possible avoid these risks. In SA, ER24 (a private ambulance service) offers a similar course, i.e. Emergency Medical Support in Hostile Environments (EMSHE). It is designed to address concerns related to violent crimes committed against their EMS personnel. The aim of EMSHE is to teach staff various skills, such as identifying hostile environments, how to deal with dangerous situations and how to mitigate the risks involved. ${ }^{[10,15]}$

We could not find literature on EMC students' perceptions of the need for HEAT. There is also debate regarding the value of HEAT. In our study, $87.61 \%$ of respondents felt that HEAT would be valuable and might mitigate the risks associated with operating in a hostile environment. Also of interest to the researcher, was that $89.38 \%$ of respondents indicated that they would feel safer knowing that they had specific training on how to handle hostile environments.

In summary, citizens of any country are exposed to varying levels of violence and crime by virtue of socioeconomic factors that influence where they live and work. The extent to which SA higher education students are to a greater or lesser degree vulnerable compared with the general population is a source of ongoing debate. Nonetheless, the mobility, age and timing of related social interactions of a typical SA higher education student are such that they have more exposure to crime and violence than the school-going population. SA higher education institutions consequently allocate significant resources towards endeavours that seek to provide safe learning and living environments on their campuses. The extent to which this responsibility covers safety for their students engaging in off-campus experiential learning placements is unclear. Additional studies need to be conducted to establish and quantify the risk profile, including the cost and feasibility of institutional initiatives and measures that seek to limit such risks.

\section{Conclusion}

This exploratory study delivers evidence suggesting that participation in clinical learning shifts in the current SA prehospital EMS environment comes with a significant risk of exposure to potentially hostile environments. Consequently, EMC students feel unsafe and support the inclusion of HEAT as part of their undergraduate degree programmes. Consideration needs to be given to include HEAT in the first year of study, before students are placed according to a roster for prehospital clinical learning shifts. Further studies are recommended that better quantify the incidence of violence toward EMC students and the impact of HEAT on their ability to manage such situations.

\section{Study limitations}

There are a number of limitations to our study. These include that the racial profile of respondents did not accurately represent that of the general population of the country. Furthermore, while we provided our participants with an overview of HEAT, we did not provide them with a detailed curriculum or suggestions about how it may be implemented in their EMC programmes. We did not focus on comparisons of responses per participating institution. We acknowledged that, as participating universities were in different provinces and cities, it is possible that responses might have differed per institution. We therefore recommend that further studies are conducted with larger stratified samples to determine the extent to which race and geography impacts on EMC students' perceptions and experiences of hostile environments and the perceived need for HEAT.

\section{Declaration. None.}

Acknowledgements. We acknowledge the participants for giving up their valuable time to complete the survey.

Author contributions. CV-L wrote the article and supervised the research on which the manuscript is based; RW gathered and analysed the data for this study.

Funding. None.

Conflicts of interest. None.

1. South African Police Service. Crime Statistics 2015 - 2016. 2016. http://www.crimestatssa.com/ (accessed 20 March 2017).

Seedat M, van Niekerk A, Jewkes R, Suffla S, Ratele K. Violence and injuries in South Africa: Prioritising an agenda for prevention. Lancet 2009;374(9694):1011-1022. https://doi.org/10.1016/S0140-6736(09)60948-X

3. Boyle M, Koritsas S, Coles J, Stanley J. A pilot study of workplace violence towards paramedics. Emerg Med 2007;24(11):760-763. https://doi.org/10.1136/emj.2007.046789

4. Boyle M, McKenna L. Paramedic student exposure to workplace violence during clinical placements - a crosssectional study. Nurse Educ Pract 2017;22:93-97. https://doi.org/10.1016/j.nepr.2017.01.001

5. Petzall K, Tällberg J, Lundin T, Ove Suserud B. Threats and violence in the Swedish pre-hospital emergency care. Int Emerg Nurs 2011;19(1):5-11. https://doi.org/10.1016/j.ienj.2010.01.004

6. Rahmani A, Hassankhani H, Mills J, Dadashzadeh A. Exposure of Iranian emergency medical technicians to workplace violence: A cross-sectional analysis. Emerg Med Australas 2012;24(1):105-110. https://doi.org/10.1111/$.1742-6723.2011$

7. Holgate $\mathrm{R}$. The opinion of emergency medical service personnel regarding safety in pre-hospital emergency care practice. Johannesburg: University of the Witwatersrand, 2015

8. Etheridge J. The hell paramedics go through to keep you alive. http://www.news24.com/SouthAfrica/News/thehell-paramedics-go-through-to-keep-you-alive-20160914? isapp=true (accessed 21 March 2017).

9. Govender K, Grainger L, Naidoo R, Macdonald R. The pending loss of advanced life support paramedics in South Africa. Afr J Emerg Med 2012;2(2):59-66. https://doi.org/10.1016/j.afjem.2011.11.001

10. Kanyane R. ER24 condemns attacks on personnel. Taung Daily News. 2016. https://taungdailynews.wordpress. com/2016/09/22/er24-condemns-attacks-on-personnel/ (accessed 21 March 2017).

11. Stein C. Faculty of Health Sciences Department of Emergency Medical Care: Learning Guide for Clinical Practice. 8th ed. Johannesburg: University of Johannesburg, 2017:1-18. http://www.uj.ac.za/EN/Faculties/health/ departments/emc/Pages/defaultaspx (accessed 3 March 2017).

12. McCusker K. Gunaydin S. Reserch using qualitative, quantitative or mixed methods and choice based on the research. Perfusion 2015;30(7):537-542. https://doi.org/10.1177/026765911455911

13. Garrett N. Textbooks for responsible data analysis in Excel. J Educ Bus 2015;90(4):169-174. https://doi.org/10.1 080/08832323.2015.1007908

14. Wongtongkam $\mathrm{N}$. An exploration of violence against paramedics, burnout and post-traumatic symptoms in two Australian ambulance services. Int J Emerg Serv 2017;6(2):134-146. https://doi.org/10.1108/IJES-03-2017-0014

15. Thusi L. EMS personnel under attack. Southern Courier. 2016. http://southerncourier.co.za/107991/emspersonnel-under-attack/ (accessed 20 March 2017).

Accepted 3 September 2018. 